\title{
La Colección Zavaleta y su traslado al Field Museum de Chicago: una aproximación desde la vida social de los objetos
}

Geraldine A. Gluzman*

\section{Resumen}

La colección de objetos arqueológicos y restos óseos humanos depositada en el Field Museum of Natural History de Chicago se inscribe dentro de una compleja trama histórica que este artículo busca explorar. Procedentes de tres provincias del Noroeste argentino (Salta, Tucumán y Catamarca) fueron adquiridos en 1904 durante la Louisiana Purchase Exposition llevada a cabo en Saint Louis (Missouri, Estados Unidos) mediante su compra directa a Manuel B. Zavaleta, su colector. Se propone analizar algunas de las principales condiciones sociales y políticas que permitieron su exposición en Saint Louis hasta su actual resguardo en el museo de Chicago y, en baja cantidad de bienes, posterior intercambio con otras instituciones. Se empleará el concepto de campo científico como espacio de tensiones entre diversos actores, instituciones y actividades para dar cuenta de las vicisitudes sufridas por las piezas desde su recuperación en Argentina. Una aproximación desde la vida social de los objetos permitirá comprender cómo los bienes arqueológicos fueron motivo de múltiples disputas sociales y de diversas lecturas de significación acerca del pasado y del futuro, no solo de las piezas sino también de los grupos indígenas contemporáneos en las postrimerías del siglo XIX e inicios del XX.

\section{The Zavaleta collection and its transfer to the Field Museum, Chicago: A social life of objects approach}

Recibido:

31 de marzo de 2017

Aceptado:

22 de agosto de 2017

\section{Palabras clave}

Colección arqueológica Zavaleta

Noroeste argentino Louisiana Purchase Exposition Field Museum of Natural History de Chicago

\section{Keywords}

Archaeological collection Zavaleta Argentine Northwest Louisiana Purchase Exposition Field Museum of Natural History of Chicago 
museum in Chicago. We also examine the exchange -in low quantities- of some of these objects with other institutions. Our article is informed by the underlying theme that the scientific field is an area of tension between different social actors, institutions and activities. This concept will be used to account for the vicissitudes suffered by these pieces since their recovery by Argentina. A social life of things approach will allow us to understand how archaeological objects were the subject of multiple social disputes and of varied perspectives concerning the past, and the future, of not only these objects but also contemporary indigenous groups at the end of the $19^{\text {th }}$ and beginning of the $20^{\text {th }}$ Century.

\section{La Colección Zavaleta, derroteros en tierras lejanas y cercanas}

La colección actualmente depositada en el Field Museum of Natural History de Chicago (en adelante, FMC) es una de las más importantes de su tipo fuera de la Argentina. Compuesta por más de 2.000 piezas arqueológicas, forma parte de las diversas y ricas colecciones arqueológicas correspondientes al período prehispánico, colonial y posiblemente moderno que generalmente se conoce como colección Zavaleta y que reúne al menos el impresionante número de aproximadamente unos 20.000 bienes (Tarragó, 2003). La misma posee materiales principalmente provenientes de los Valles Calchaquíes (cubriendo las provincias de Salta, Tucumán y Catamarca). Recopilada por Manuel B. Zavaleta, hoy día los objetos arqueológicos se encuentran distribuidos principalmente en cuatro instituciones: el Museo Etnográfico “J. B. Ambrosetti” de Buenos Aires, el Museo de Ciencias Naturales de La Plata, el Museo Etnológico de Berlín y el FMC. La porción correspondiente a Chicago le sigue en cantidad a la del Museo Etnográfico, donde se encuentra más de la mitad de la misma. Si bien en el extranjero, ha contribuido enormemente en el conocimiento de las sociedades pasadas del Noroeste argentino (NOA).

Manuel B. Zavaleta (1862-1925) fue uno de los más importantes colectores de piezas prehispánicas entre fines del siglo XIX y comienzos del XX del NOA. Estanciero y comerciante nacido en Salta, residió en Tucumán y realizó emprendimientos como la cría de hacienda para la venta, la fabricación de hielo en la ciudad de Tucumán y el ejercicio del puesto de comisario de policía en el valle de Tafí (Farro, 2008). Destinadas a la comercialización y venta, Zavaleta aprovechó su posición económica y social en el área para tener acceso a conocimientos directos de cementerios y áreas de riqueza arqueológica al tiempo que guardó celosamente las procedencias específicas de los especímenes para que nadie interfiriera en la obtención futura de piezas similares allí (Tarragó, 2003), tema que Farro (2008) explica en su tesis doctoral. Contactos generados a partir del negocio de hacienda le permitieron vincularse con la venta de antigüedades y, previamente, a la de la ubicación de un tesoro escondido o "tapado", básicamente de oro y plata. Zavaleta llevó a cabo esta actividad en un nivel regional gracias al conocimiento directo acerca de áreas ricas en piezas arqueológicas, a diferencia de otros buscadores de "tapados" a nivel local (formando colecciones en los alrededores de sus pueblos y vendiéndolas al mejor postor), y la posibilidad de resolución de problemas vinculados a la organización del trabajo, como la obtención de mano de obra, alquiler de mulas y el transporte, carga y embalaje (Farro, 2008). El ejercicio inescrupuloso del cargo de policía le habría permitido contratar mano de obra barata y en abundancia (ya que los comisarios de policía eran los que ejercían el control y manejo de la peonada), el permiso de acceso por parte de los propietarios o de la autoridad policial a los campos en donde se hallaban las ruinas y mantener en secreto dichas áreas (Farro, 2008; Tarragó, 2003). La venta de piezas arqueológicas no fue tampoco su único tráfico de objetos en el mercado ya que también se dedicó, sobre todo al inicio de estas actividades, a 
la comercialización de fósiles (Ameghino, 1891), minerales (Farro, 2008; Scattolin, 2003) y ejemplares de animales (Holmberg, 1887). Como se retomará, su capacidad de adquisición y venta de objetos, de articulación de diversas actividades económicas y de movimiento entre diferentes actores e instituciones le permitió hacerse de considerables sumas de dinero, así como acceder a un capital simbólico en el exterior que supo cosechar para aumentar su fortuna económica.

A lo largo de sus más de veinte años de actividad en el negocio de comercio de piezas arqueológicas, Zavaleta las venderá mediante solicitudes personales a ser tratadas en el Congreso de la Nación, a través del Ministerio de Instrucción Pública, gobiernos provinciales o mediante la negociación personal con entidades educativas y académicas. Tan temprano como inicios de enero de 1885, Florentino Ameghino revisó la colección de fósiles y objetos arqueológicos de los valles Calchaquíes que había recolectado Zavaleta, interesado fundamentalmente en los restos de un gliptodonte. Zavaleta publicó en la prensa acerca de sus colecciones ese mismo año y Ameghino respondió a la misma agregando la historia del descubrimiento de esta especie (Ameghino, 1891). Asimismo, el 21 de enero de 1885, el diario tucumano El Orden expresaba: "llenos de legítima curiosidad y placer hemos examinado las colecciones científicas que el estimable joven Manuel B. Zavaleta ha traído consigo como resultado de sus excursiones por el vasto ramal del Aconquija" (en Peña de Bascary, 2014, p. 6).

Mediante solicitudes al Ministerio de Instrucción Pública, Zavaleta efectuó tres ventas de conjuntos de antigüedades calchaquíes y de restos de mamíferos extinguidos en 1885, 1887 y 1889 (esta última para el Museo Nacional de la Ciudad de Córdoba) (Argentina. Ministerio de Justicia, Culto e Instrucción Pública, 1897, p. 181; Argentina. Ministerio de Justicia, Culto e Instrucción Pública, 1899, p. 17; Farro, 2008, p. 209). Una colección importante de antigüedades procedentes de los valles Calchaquíes también fue vendida en 1888 y destinada al Museo de La Plata, cuando Francisco P. Moreno era su director. Compuesta de unas 400 piezas y ocho cráneos, se vendió por 16.500 pesos nacionales (Farro, 2008).

Zavaleta comenzó la venta de su colección hacia 1899 cuando se promulga la ley 3.799, "Colección de antigüedades calchaquíes" en el Congreso Nacional, la cual acepta la propuesta de venta de Zavaleta a entregar al Museo Nacional (hoy Museo Argentino de Ciencias Naturales "Bernardino Rivadavia"), abonada mediante tierras públicas disponibles en los territorios de la Pampa Central y Chubut (Bertone et al., 1991). Diferentes investigadores consultados, entre ellos el Dr. Carlos Berg, director del Museo Nacional, Florentino Ameghino, Samuel Lafone Quevedo, el General Mitre, Juan B. Ambrosetti y Adán Quiroga, "aconsejan su compra, pues se trata de una colección de gran valor histórico, que se relaciona con los antiguos habitantes de las comarcas que en la actualidad constituyen la República Argentina" (Bertone et al., 1991, p. 100). Se agrega que dichos materiales pueden convertirse en el primer paso para la creación de un museo arqueológico (Bertone et al., 1991). Se trataba de 2.009 piezas y el costo equivalía a un $20 \%$ más que el presupuesto anual del Museo Nacional (De Asúa, 2012). En 1907 una segunda y última adquisición de "antigüedades calchaquíes" a Zavaleta fue aprobada en el Congreso Nacional. La venta fue en moneda nacional pero su valor proporcional por pieza fue menor ya que se adquieren 11.590 objetos por 35.000 pesos. Al igual que la vez anterior se pidió asesoramiento a Ameghino "persona competentísima que conoce a fondo esta clase de estudios arqueológicos y antropológicos" (Lenton, 2005, p. 194). Como ya había realizado parcialmente en su venta de piezas en Saint Louis, Zavaleta acompañó el pedido con un Catálogo (Zavaleta, 1906) donde se menciona el tipo y la procedencia de los bienes arqueológicos y cráneos humanos junto con más de 60 fotografías de las piezas, de sus contextos inmediatos y sus ámbitos regionales de recolección. Estas dos ventas de colecciones pasarían al Museo Etnográfico de la Universidad de Buenos Aires hacia 1947 (Pegoraro, 2009). 
Farro (2008) aporta información adicional acerca de la venta de piezas arqueológicas y antropológicas al Musée d'Ethnographie du Trocadéro cuando Zavaleta viajó a París en 1897 para ofrecerlas a las principales instituciones interesadas en temáticas americanistas y tras exhibir en ese museo la colección al público general (también Petitjean, 1897). Otra importante comercialización de material del NOA al exterior ocurrió en 1906 cuando Zavaleta vendió un lote de 5.000 piezas aproximadamente al Museo Etnológico de Berlín, por el precio de 100.000 marcos, el más alto en su historia de compra de colecciones americanas (Fischer, 2010). Dentro de estos envíos al extranjero se inscribe la colección aquí analizada.

\section{La Colección Zavaleta en la Feria de Saint Louis}

Los materiales que conformarían la colección Zavaleta del FMC fueron adquiridos por compra directa a Manuel Zavaleta prácticamente al cierre de la Louisiana Purchase Exposition (en adelante, LPE) llevada a cabo en Saint Louis durante los meses de abril a noviembre de 1904. Esta exposición formaba parte de aquellas ferias mundiales que crecieron en popularidad durante el siglo XIX e inicios del XX y donde las naciones participaban con vitrinas y pabellones que cristalizaban sus maravillas culturales y naturales, al tiempo que reflejaban cómo ellas mismas se auto-referenciaban (Parezo y Munro, 2010; Penhos, 2009). Los pabellones de las diferentes naciones estaban planificados para presentar sus ideales acerca del progreso social, sus lineamientos políticos y económicos y su entendimiento acerca del pasado, presente y futuro dentro del panorama mundial. En líneas generales lo que movilizaba a participar en la feria era la posibilidad de hacerse conocer de un modo particular que potenciara beneficios económicos a largo plazo. Las recientes naciones americanas también estaban concentradas en mostrar la interacción entre sus idearios sociales vigentes y las poblaciones indígenas. Estos países se acercaron de tres modos diferentes al tema: a) invisibilizando a la población indígena, sin hacer mención de ésta en los diversos ámbitos de la feria; b) tomando a la población indígena como limitador para el desarrollo económico, progreso tecnológico y avance pleno hacia la modernidad y, al mismo tiempo, mostrando hasta qué punto las nuevas naciones habían, a pesar de esta condición, prosperado en términos evolutivos culturales y c) elogiando los logros artísticos y la capacidad de los grupos indígenas de localizar recursos naturales provechosos, invitando a realizar inversiones extranjeras para explotarlos (Parezo y Munro, 2010). La celebración de un pasado indígena no necesariamente implicaba establecer lazos históricos con el presente contemporáneo sino únicamente agregaba una dimensión digna de estudio y admiración aunque previa a la conformación de la nación en sí (Haber, 1999).

A diferencia de otras participaciones, como la de París de 1889, que sobresalió por la majestuosidad y avance tecnológico de la arquitectura de su pabellón, la representación oficial de la Argentina en Saint Louis fue más reducida debido a las tensiones entre el poder ejecutivo que aceptó la invitación de participación por el gobierno de Estados Unidos en 1902 y la cámara de senadores del poder legislativo que cuestionó la conveniencia de acudir a esa clase de eventos alegando una supuesta escasez de industria nacional y a la mala propaganda de llevar, tal como había sucedido en París, "lazos, cabezadas y recados y artículos de manufacturas de quichuas y demás indios" como exponente de la industria local (Penhos, 2009, p. 63, ver allí la discusión detallada en el Congreso de la Nación, pp. 63-66).

La LPE albergó a más de 60 naciones en un predio de casi 500 hectáreas y recibió prácticamente 20 millones de personas, un promedio de cien mil visitantes por día, constituyendo un espacio ideal para conocer los últimos logros en una variedad de temáticas, desde tecnología y ciencia, industrias y explotación de recursos naturales 
a educación, política exterior y artes. Cuestiones antropológicas tuvieron también un papel destacado. Los organizadores consideraban que este ámbito, donde lo exótico estaba al alcance de la vista a través de la recreación de entornos ambientales y sociales etnográficos, enseñaría a los visitantes el progreso que los países modernos habían hecho en aspectos culturales y tecnológicos. Hombres, mujeres y niños de África, Asia, Europa y América ejecutaban y mostraban costumbres tradicionales estereotipadas por el hombre occidental para educar a los visitantes sobre sus culturas primitivas y exóticas (Parezo y Fowler, 2007). Lo mismo ocurría con los artefactos arqueológicos, poderosas curiosidades de un tiempo pretérito provenientes de zonas alejadas. Pero asimismo debe tenerse en cuenta el matiz comercial -y de adquisición de lo "exótico" para los nacientes museos norteamericanos- de la feria. En lo que hace al departamento de antropología de la LPE, una parte de las actividades estuvo destinada a convocar a aquellos que poseyeran colecciones de materiales etnográficos y arqueológicos a ser expuestos para su venta. Más de cincuenta mil artefactos fueron depositados solo en el edificio de antropología, sumando "decenas de miles de artículos de cultura material" expuestos en pabellones dispersos a través de la exposición (Parezo y Munro, 2010, p. 31).

El pabellón argentino (una reproducción parcial del palacio de gobierno en Buenos Aires) abrió recién el 9 de julio con una recepción informal a la que asistieron el presidente, David Francis, y directores de la exposición y otros delegados extranjeros y de los Estados Unidos (Francis, 1913). Los visitantes fueron recibidos por el Dr. José Fernández (Comisionado General), Ernesto Nelson (Comisionado de Educación), Eduardo Schiaffino (Comisionado de Bellas Artes), Enrique Nelson (Comisionado de Agricultura y Silvicultura), Guillermo Puente (Comisionado de Producción y Electricidad), ingeniero Horacio Anasagasti (Comisionado de Minería), Dr. Damián Lan (Comisionado de Ganadería), Dr. Luis Sauze (Comisionado Honorario) y José de Olivares (Comisionado de Prensa) (Francis, 1913). La comitiva oficial también se componía de delegados del consejo nacional de educación, del congreso de mujeres, de la asociación argentina de prensa y del congreso de electricidad (Stevens, 1904). En las publicaciones consultadas, realizadas por la organización de la feria, no se menciona a Manuel Zavaleta como representante oficial del gobierno argentino. Tampoco aparece mencionado como tal en la prensa local dedicada a la descripción de participantes ("Comisión Argentina en la exposición de San Luis", 1904, "Argentinos en la exposición de San Luis", 1904). Sin embargo es de estimar que se haya encontrado presente desde entonces ya que no solo se encargó del arreglo de la colección (Parezo y Munro, 2010; Penhos, 2009) sino que la prensa estadounidense resaltó su presencia en Washington los días previos a la feria.

Argentina ofreció un amplio espectro de exposiciones, destacándose aquellas en los palacios de Agricultura, Minas, Producción y Electricidad, Bellas Artes y Educación. Más allá de cómo Argentina buscara presentarse, sobresalió como país esencialmente agrícola-ganadero con una importante producción de maquinarias industriales necesarias para abastecer a la población local en crecimiento (Penhos, 2009). Asimismo el sistema educativo fue resaltado como eje apreciable de desarrollo del país (Louisiana Purchase Exposition Commission, 1906). Fotografías dispuestas en paredes, álbumes y aparatos estereoscópicos mostraban a las principales ciudades, exponiendo la arquitectura de edificios, puertos y obras públicas. Argentina cumplió su cometido de autorepresentación ya que es vista como el país más progresista de Sudamérica (Louisiana Purchase Exposition Commission, 1906) a la par de las naciones europeas o la norteamericana. Pero además de estos logros, el segundo piso del pabellón argentino, diseñado originalmente como una sala de conferencias, fue reconsiderado para otro propósito cuando el "distinguido ciudadano argentino" Zavaleta hizo una oferta para exhibir su "notable colección arqueológica y antropológica" (Buel, 1904, p. 2186, traducción de la autora) de la región Calchaquí y complementada con materiales 
de Ancón y Chimbote, Perú. Asimismo se repara en que es el coleccionista quien paga los costos de traslado de las piezas a la feria (Buel, 1904). Es decir, ante la oferta de Zavaleta, hubo una preocupación dirigida a la representación de la Nación como un todo, más allá de sus polos de progreso (Lenton, 2005). Sin embargo, su armado y narrativa estuvieron al margen de los recientes museos, universidades y estudiosos reconocidos como Ambrosetti, Lafone-Quevedo, Quiroga o Moreno. El valor cultural y estético de los grupos calchaquíes, visto por estos tres primeros arqueólogos no se hizo presente en esta exposición.

Estas muestras y traslados al exterior, al tiempo que eran los ámbitos privilegiados para ventas con altas ganancias, le otorgaban capital simbólico a Zavaleta y buena fama a su colección, al haber sido bien recepcionado por amplias audiencias académicas y no académicas. En la feria su participación fue vista del siguiente modo:

Este interesante museo de reliquias de razas sudamericanas prehistóricas es el resultado de casi treinta años de investigación paciente e inteligente y de trabajo en la recolección de objetos producidos por pueblos antiguos, con la visión no sólo de mostrar su condición social antes de la invasión española, sino también para demostrar el paralelismo que existía en la cultura de los dos continentes americanos [América del Norte y Sur] (Buel, 1904, pp. 2186-2187, traducción de la autora).

Días previos a la apertura del pabellón argentino, el diario New York Tribune informa la presencia de algunos de los miembros de la comisión argentina del LPE en la Casa Blanca (Washington DC) y describe a Zavaleta como el arqueólogo más importante de la Argentina ("At the White House", 1904). Asimismo, el Washington Times resaltaba que la inmensa colección de antigüedades y curiosidades naturales requirió su traslado en 42 grandes cajas ("Exhibit of Argentina's Prehistoric People", 1904).

Zavaleta como coleccionista e inversionista privado pero bajo el auspicio del gobierno nacional fue principalmente quien promovió en la LPE su visión particular de las poblaciones prehispánicas del NOA a través de la selección de la cultura material al decidir la disposición y arreglo de las colecciones tanto en el pabellón como en el edificio de antropología (Parezo y Munro, 2010). Posiblemente las vitrinas estuvieran acompañadas por las fotos que también vendió al FMC más tarde. De la totalidad de esas materialidades, subyacía una visión del mundo social prehispánico con poca conexión con la sociedad argentina contemporánea, concentrada en las grandes ciudades y medios de transporte que cubrían el vasto territorio. Sin embargo como nación moderna, la colección le otorgaba un motivo de orgullo de un pasado glorioso, aunque sin conexión con el presente. Es posiblemente por esta conexión indirecta con la nación que las piezas arqueológicas obtenidas en Perú -y que no fueron expuestas en ninguna de las instalaciones de este país aun cuando su número era considerable- pudieron ser exhibidas sin contradicciones discursivas con la idea de nación que el pabellón argentino buscaba fomentar. De igual forma, la mayoría de las cerámicas enteras moche podían remitir al gusto estético del pabellón, ya que las mismas posiblemente eran representantes de las Bellas Artes universales, con diseños basados en el orden, la consistencia, el ritmo, la armonía y el equilibrio de las líneas, formas, masas, colores, valores de luz y textura (Lewis, 1961), mientras que los objetos del NOA eran en ocasiones fragmentos de piezas cerámicas. Contraparte de esa perspectiva estática y pasada fue la concurrencia de un grupo de tehuelches que habían sido enfáticamente trasladados y pagados desde la comitiva oficial de la exposición y cuyo principal objetivo era mostrar la variedad de la raza humana. El grupo de los "patagones gigantes", que llegó a mediados de abril, es decir independientemente de la apertura del pabellón argentino, se componía de una familia extensa de cinco hombres adultos, una mujer adulta, y una niña (Parezo y Fowler, 2007) que se caracterizaban, según los anuncios de LPE, por su gran estatura, robustez 
corporal y fuerza física, así como por su habilidad como cazadores y jinetes (Louisiana Purchase Exposition, 1904). Viviendo en toldos y junto a canoas, estos patagones estaban artificialmente escenificados en un ámbito similar al de su entorno patagónico original. Sin embargo, "la gente más alta del mundo" (Official Guide Company, 1904, p. 74, traducción de la autora), como se los definía, estaba también en proximidad espacial a otra recreación ambiental, la de los pigmeos del África Central, a fin de que el público pudiera ver los extremos de alturas de la raza humana (Official Guide Company, 1904). Estos rasgos físicos sumados a los juegos de boleadoras y monta de caballos constituían medios ideales para divertir a los visitantes y mostrar a grupos humanos que parecían vivir en otro tiempo, en una suerte de negación de su contemporaneidad (Fabian, 2002).

De la totalidad de objetos, 647 para la región del NOA (y 46 para los de Perú) son mencionados en la publicación oficial. El listado sigue los lineamientos de descripción parcial que son vistos en el catálogo de 1906 que publicara Zavaleta. Pucos, vasos, platos, jarras pequeñas, cantaros y urnas funerarias son numerados así como ídolos en cerámica los que aluden casi siempre a figuras antropomorfas. Se distinguen piezas pintadas o sin decoración, y muchas veces se mencionan sus tamaños relativos. Similares descripciones se dan para otras materias primas. Un ejemplo en metal es: "935. Hacha de cobre, con figuras y dibujos. San Isidro" (Louisiana Purchase Exposition, 1904, p. 29 , traducción de la autora). Es muy posible que esta numeración correspondiera a la dada por Zavaleta del mismo modo que la descripción (como el caso "199. campana o tamtam") y referencia geográfica (aunque muchas veces están mal tipeadas, como el caso de Quilmos por Quilmes). Las descripciones tampoco permiten indagar cronología, con excepción de un estribo de cobre procedente de Amaicha, de origen posthispánico.

La única fuente de información acerca de la disposición de los objetos de la colección Zavaleta en la feria procede de Parezo y Munro (2010). Según las autoras, esta exposición de materiales arqueológicos fue una de las más numerosas de la feria, donde si bien la de Zavaleta fue la más importante, hubo contribuciones menores a cargo de provincias del Norte del país ${ }^{1}$. Estas últimas se habrían ubicado en el edificio de antropología, así como la mitad de la colección Zavaleta (Parezo y Munro, 2010). Las vitrinas estaban organizadas de acuerdo a materia prima, tamaño y tipo de material y las descripciones de guía son consideradas por estas investigadoras como minimalistas, destinadas simplemente a orientar al visitante a quien se dejaba el uso libre de sus marcos de referencia interpretativos y estéticos, ya que el mensaje general, connotando la idea de gente y regiones primitivas en oposición a la tecnología que abundaba en el resto de feria, se sobreentendía. Invitado especialmente por Zavaleta para que mirase la colección de cráneos calchaquíes ("Notes of Happenings at the World's Fair", 1904), algunos ejemplares llamaron la atención al Dr. William McGee, jefe del Departamento de Antropología de la feria, debido a que poseían evidencias de trepanaciones, hecho que, tal como escribe un periodista, incluso había pasado inadvertido por Zavaleta ("Scars on skulls interest scientist", 1904). En lo que hace a las piezas peruanas, la mayoría son clasificadas como huacos, denominación provista posiblemente por el colector en Perú y que Zavaleta simplemente copiara. Finalmente se destaca que dentro de los entretenimientos, y como modo de valorar las colecciones presentadas, se entregaron premios dentro del departamento de antropología, para diversas categorías. Zavaleta obtuvo el máximo galardón por su colección en el rubro de arqueología (Hewett et al., 1905). Durante la feria no hay una diferenciación en los comentarios acerca de las antigüedades calchaquíes de las peruanas, formando un todo poco clasificado social, espacial y temporalmente.

\section{La Colección Zavaleta en el Field Museum de Chicago}

La colección Zavaleta en el FMC se compone de los materiales culturales y restos esqueletales humanos actualmente presentes, de los registros fotográficos que
1. Según Parezo y Munro (2010, tabla 3) los distritos de Tucumán y Salta participaron en forma individual enviando materiales arqueológicos. No hemos encontrado esta información en otra fuente de la época o bibliografía sobre la feria. Lamentablemente no hay una cita específica dónde buscar dicha información y analizar la fuente original consultada. 
2. Es difícil estimar el valor relativo de U\$S17.000 en 1904, cuando se trata de bienes no destinados al consumo. Es posible establecer un valor mínimo y uno máximo de acuerdo a diversos parámetros económicos. Considerando la categoría de bien de consumo, una estimación del monto a 2015 sería de U\$S 362.00o, contemplando únicamente la inflación. Evaluando el poder económico, medida que observa la cantidad de ingreso en relación con la producción total de una economía, su equivalencia actual es de U\$S 11.800.000. Un valor medio es aquel que expresa el estatus de un bien y que se estima en U\$S 3.030.000 (Williamson,

2017). acompañaron la compra y los archivos históricos, clasificados como Accession $\mathrm{N}^{\circ} 894$ (1904) y Accession $N^{\circ} 971$ (1905). La colección Zavaleta se adquirió por U\$S 17.000². La prensa local se hizo eco de la noticia y describe a la colección como la primera gran exhibición vendida ("First Exhibit Sold", 1904). El diario enfatizaba que, de acuerdo a McGee "Hay una gran diferencia a encontrar en el trabajo más reciente realizado por los indios Calchaquíes de la última centuria o dos y el trabajo representado por sus ancestros primitivos" ("First Exhibit Sold", 1904, traducción de la autora). Agrega:

El trabajo de los indios primitivos es rico en la representación del folklore y símbolos de sus tribus particulares. Las cabezas de varios animales que ellos veneraban, y con las cuales ornamentan mucha de la cerámica, está faltando en el trabajo más moderno de esta gente (...) donde el hombre blanco ha dejado su impronta sobre los pueblos incivilizados, luego el espíritu de preservación de los símbolos tribales pierde su importancia (“First Exhibit Sold”, 1904, traducción de la autora).

Esta frase no es casual si se considera que la colección Zavaleta poseía muchos mamelones cerámicos. Evidentemente esta información, solo factible de ser aportada por el mismo Zavaleta, debió justificar la presencia de estos fragmentos. Lejos de perder valor, los mismos representaban símbolos que el calchaquí contemporáneo ya no conocía y cuyo estudio podía aportar al entendimiento de sus significados. La prensa de otros estados del país también se hicieron eco de la noticia, en ocasiones sobredimensionando la colección por la cual se habrían pagado hasta U\$S 100.000 (entre otros, "Chicago gets rare relics”, 1904). El diario argentino La Nación celebraba el 17 de noviembre de 1904 la venta de la "colección Zavaleta" que había "llamado extraordinariamente la impresión de arqueólogos y antropologistas". Describía la colección poseyendo "numerosos objetos de barro cocido, instrumentos de cobre, muchos ídolos admirablemente conservados y una colección de cráneos que, según los especialistas, constituye el principal interés, desde el punto de vista de la antropología sudamericana”. El artículo finalizaba viendo a Zavaleta como exitoso hombre de negocios: "Llenado el objeto de su viaje, el señor Zavaleta partirá en seguida para Londres y Alemania”.

De este modo, a lo largo de su exhibición y durante los primeros años de su depósito en el FMC se esgrimieron las siguientes razones para la compra y, en definitiva, para determinar su importancia de estudio y conservación: a) diversidad, riqueza decorativa y cantidad de piezas (las urnas funerarias en particular -cuyas curiosas decoraciones convencionales derivan de motivos vivos- y las formas inusuales de algunos implementos de cobre) (Starr, 1905); b) contraste con la producción material de los grupos calchaquíes contemporáneos; c) tipo de trepanaciones en cráneos y diferencias con aquellos de otras áreas andinas; d) paralelismos entre los grupos calchaquíes y los indios del sudoeste americano, ya consignado por Ambrosetti (entre otros, 1896). Asimismo un valor extra le otorgaba la figura de Zavaleta como representante del estudioso con amplia experiencia de casi tres décadas que supera fronteras y arma grandes colecciones frente a las vicisitudes propias de una tierra lejana e inhóspita.

La colección se describe en una de las primeras referencias que se encuentran en el archivo documental del FMC como una "archaeological collection from province of Calchaqui and Peru" y hay correspondencia de conformidad de partes el 14 de octubre de 1904. El FMC había sido recientemente creado ya que tuvo su origen en otra feria internacional, la World's Columbian Exposition celebrada en Chicago (1893). Diez años después, y aun bajo la dirección del profesor Frederick Skiff, el museo seguía ávido de obtener piezas arqueológicas de América del Sur y sobre todo de aquellas regiones pobre (como Perú, en sus cerámicas moche) o nulamente representadas (como Argentina) ya que uno de sus objetivos era alcanzar un nivel de educación de excelencia para la audiencia en todos los ámbitos de la ciencia a escala mundial (Dorsey, 1900). 
Desde ese entonces, la colección Zavaleta del FMC ha sido analizada en varias oportunidades (Accession Nº 894, 1904). Por ejemplo, Alberto González realizó la identificación y asignación cronológica de 13 cerámicas en 1973, y un hacha del tipo " $\mathrm{T}$ " con salientes para atar al mango fue solicitada en 1985 para realizar estudios metalográficos por J. L. Hollowell y como resultado la pieza se dividió por la mitad. R. Weber contribuyó a la seriación de urnas Santamarianas y su análisis iconográfico (1978, 1981), mientras que M. C. Scattolin (2003, 2006a, 2006b) abordó el estudio de cerámicas tempranas en términos cronológicos y estilísticos. Quien escribe realizó en 2014 un registro archivístico, fotográfico, tipológico, composicional y de procedencia de más de 180 piezas de metal, cuyos resultados próximamente serán publicados. Paralelamente una breve observación de la colección depositada permitió registrar el destino final de piezas publicadas en fechas tan tempranas como 1893. Es el caso de una figurina humana femenina de piedra que fuera originalmente divulgada por Ten Kate, quien en Molinos (Salta) le hizo un molde de yeso y publica su croquis (Ten Kate, 1893, figura 8). Años más tarde Ambrosetti (1899, figura 24) habría tenido acceso al molde en yeso depositado en el Museo de La Plata. Con un dibujo más acabado, toma nota de que fue hallado por Enrique Mariani y su pertenencia a la colección Zavaleta. Hoy, con el número 101.892, la misma está asignada a San Carlos. Al momento no es posible reconocer los motivos detrás del cambio de procedencia.

De la lectura de los archivos se desprende que mientras que la pequeña porción de la colección Zavaleta de Perú fue prestada para diversas exhibiciones o solicitada para la reproducción de imágenes en revistas, libros e incluso una cerámica retrato fue reproducida en el calendario anual de 1987 de la institución, la porción de "Calchaqui" fue sobre todo motivo de intercambios con otros museos (Accession $\left.\mathrm{N}^{\circ} 894,1904\right)^{3}$. El análisis de los registros indicaría que los restos óseos humanos no fueron intercambiados (Accession $\mathrm{N}^{\circ}$ 971, 1905). Dentro de los intercambios a nivel nacional mencionamos el Museum of American Indian con dos entregas $(1918,1919)$, sumando un mínimo de 347 piezas $^{4}$. El Peabody Museum (Harvard University) posee cuatro ejemplares y de acuerdo a los datos consignados en su base de datos en línea se trataría de tres hachas de piedra y una figurina de mamífero cuadrúpedo ${ }^{5}$. En la década de 1930 se efectuaron intercambios de materiales con el Gila Pueblo Archaeological Foundation (hoy depositados en la Universidad de Arizona), contemplando cinco hachas de piedra y cuatro cerámicas. En 1931 se realizó un intercambio de materiales con el actual Penn Museum (Universidad de Pennsylvania, Philadelphia) ${ }^{6}$.

Detrás de esta política institucional subyació la idea de ser los materiales calchaquíes menos valiosos, en ocasiones aludiendo a su falta de contexto o por la alta cantidad de piezas. Sin embargo, el número de piezas intercambiadas no es tanto como parece a primera vista ya que en 1919 se informa que la colección Zavaleta de Calchaquí compuesta por 4.294 artefactos fue reclasificada en 2.120 números de catálogo (Field Museum of Natural History, 1919, pp. 233-234), haciendo difícil reconstruir su historia íntegramente. Hoy día el catálogo de objetos arqueológicos para el NOA se conforma de un total de más de 1.500 bienes sin contar restos humanos. El fragmento de un fósil y de guijarros también completa la lista.

\section{Manuel Zavaleta y la conformación del campo científico}

Las prácticas de recolección de objetos ejercidas por Zavaleta y su alta visibilidad social se inscriben en un momento de constitución del campo científico de la arqueología, marcado por relaciones de fuerza, luchas, estrategias, intereses y beneficios (Bourdieu, 2000) y en donde el Estado Nación no era ajeno a dichas tensiones. Se ha visto como éste, mediante el poder ejecutivo y el legislativo, tanto con alcance nacional o provincial, aprobó la compra de diversos lotes de colecciones conformadas por Zavaleta. ¿Qué
3. Una hachita lítica de Tafí fue solicitada en préstamo para un documental, “¿Qué es el dinero?” (Coronet Instructional Films, 1947) como ejemplo de mercancía en tiempos primitivos.

4. Posiblemente los siguientes objetos del catálogo en línea del MAI correspondan a la colección Zavaleta, si bien allí se describen de historia desconocida, anteriormente en el FMC (http:// www.nmai.si.edu/searchcollections/ home.aspx): puntas de flecha en hueso de Fuerte Quemado, puntas e instrumentos tallados en obsidiana y otras materias primas líticas de Tafí del Valle.

5. Nos referimos a los siguientes objetos: efigie de cuadrúpedo en piedra de Cafayate, hachas de piedra con ranura de Amblayo y hacha de piedra con ranura de Tafí. En los registros no hay datos acerca de la historia de su adquisición pero debido al tipo de objetos, procedencias y descripciones se tratarían de materiales de la colección Zavaleta. http://pmem. unix.fas.harvard.edu:8080/ peabody/

6. A través del catálogo en línea de la institución pueden conocerse los materiales intercambiados (www.penn.museum/collections/ list.php?id=4476). A saber: collar de cuentas de turquesas, piedras verdes similares y metal, urnas y olla de Tucumán; jarros (pitcher) de Salta; puco y urna de Argentina. 
factores incidieron para que Zavaleta, criticado ampliamente por varios sectores de ámbitos académicos, pudiera instrumentar los medios necesarios para vender parte de su colección al FMC? Un recorrido por varios eventos de su carrera como comerciante ofrece un panorama al respecto. Ya en etapas tan tempranas como 1888, Moreno observaba:

El sistema de exploraciones bien dirigidas y sin que de ellas se ocupen los periódicos que despiertan el interés comercial, es el más económico a mi modo de ver para llevar a muy grande altura nuestro Museo. En él se suprime la compra de colecciones innecesarias cuando no se trata de objetos únicos, y en apoyo de lo que dejo manifestado está el caso de la colección arqueológica del Sr. Zavaleta (Farro, 2008, p. 211).

En esta frase hay una síntesis de muchos aspectos a destacar, que serán abordados en esta sección.

\section{Modalidad de obtención de los objetos y su transformación en mercancías}

Gran parte de las instituciones académicas no aprobaba las prácticas de excavación clandestinas y nada rigurosas llevadas a cabo por Zavaleta; para quienes el valor de las piezas radicaba en el conocimiento de las sociedades pasadas y no en el interés económico.

En un breve viaje exploratorio por los valles Calchaquíes en 1897, Henry de la Vaulx, miembro de la Société des Américanistes de París, encontró rastros de un huaqueo que habría sido ejecutado por Zavaleta en las cercanías a Quilmes. Considera que estos vestigios muestran el accionar de gauchos ignorantes realizando excavaciones sin orden ni método que condujeron a resultados ínfimos (de la Vaulx, 1901, p. 169). Con los materiales allí dejados, de la Vaulx realizó una clasificación tipológica de urnas y pucos, contemplando formas y decoraciones. Sin duda fue a Lafone-Quevedo quien, hacia 1900 ya ocupando la dirección del Museo de La Plata, le causaba mayor preocupación el accionar de Zavaleta y cómo esta podía fomentar prácticas de saqueo, al tiempo que criticaba el rol pasivo del estado en detener esas actividades (Farro, 2008).

Asimismo no se trataba únicamente de la modalidad de excavación sino de las falsificaciones en las colecciones, como las vendidas al museo de La Plata, y las procedencias mal consignadas (Farro, 2008), las cuales reducían la confiabilidad de los hallazgos. Por tal motivo Moreno consideraba fundamental la realización de una expedición arqueológica al NOA ya que el museo obtendría a menor precio abundantes materiales con autenticidad asegurada (Farro, 2008).

\section{Articulación de diversos organismos, agencias, público general y expertos}

Asimismo Moreno resaltaba una de las principales características que Zavaleta supo lograr: reunir diferentes actores y usar a la prensa para adquirir prestigio, reconocimiento y crédito económico e institucional. Y clave en este logro fue que recurrió a la autoridad científica que él no poseía. Farro (2008) aporta información acerca de una serie de correspondencias personales entre Zavaleta y Ameghino. En una carta de 1885 Ameghino explicó la importancia que tenían las colecciones desde el punto de vista científico, argumentos que Zavaleta transcribió textualmente en su carta de ofrecimiento de la colección para su venta al Ministerio de Instrucción Pública. En una carta de 1889 Ameghino escribe:

Me pide usted mi opinión sobre la nueva colección de antigüedades calchaquíes que ayer tuve el placer de examinar, aunque es la tercera o cuarta vez que me hace 
idéntico pedido, accedo gustoso, porque contemplo con verdadera satisfacción el cúmulo de objetos interesantísimos que sucesivamente ha sabido usted reunir (Farro, 2008, apéndice IV-I, ítem 11).

Además había al menos una tácita autorización al estudio de las piezas, a su reproducción total o de diseños y hasta una concesión de las piezas a museos. Lo primero puede verse en las ilustraciones que reproducen algunas de estas piezas (Ambrosetti, 1896), las que se encontraban en ese momento en el Museo Nacional. Lo mismo pasaba con aquellas piezas paleontológicas comercializadas por Zavaleta y adquiridas por museos (Ameghino, 1891; Burmeister, 1891). En una época donde los materiales arqueológicos del NOA escaseaban, poder recurrir al estudio y publicación de los materiales suministrados por Zavaleta despertaría reconocimiento. $\mathrm{Y}$ a su vez, ese caudal de información publicada le servía a Zavaleta para demostrar la excelencia de sus hallazgos. Como fuera ya señalado previamente, fuera de los ámbitos académicos, Zavaleta supo gozar de popularidad y renombre y la prensa escrita le festejó las ventas nacionales e internacionales equiparando objetos arqueológicos con mercancías comerciales. Zavaleta era visto como exitoso argentino dado que desde el lejano Tucumán sus colecciones eran solicitadas en el mundo entero.

\section{Maximización del beneficio y de los objetos museables}

Hacia 1893 Max Uhle "se espanta de los precios que Zavaleta es capaz de pagar por piezas arqueológicas y sobretodo los precios que consigue por sus colecciones vendiéndolas a universidades y museos argentinos" (Fischer, 2010, p. 53). Es decir, no solo se trata de la compra en sí, sino de los altos costos, que permitían realizar excavaciones más metódicas. Sin embargo, la compra directa implicaba el éxito garantizado del objeto, mientras todo viaje llevaba un riesgo y conseguir un menor número de piezas. Es decir, Zavaleta consigue su cometido como ningún otro comerciante de piezas arqueológicas de la época por el caudal de piezas y tipos diferentes, así como también cubrir un amplio marco regional. Ya se mencionó que la red de comercio que vinculaba el ganado y su puesto de comisario de policía le proporcionaron sólidas bases para lograr un conocimiento ajustado de áreas ricas en materiales demandados, la autorización a ingresar a terrenos de terceros, la recuperación de los mismos mediante el acceso a mano de obra, el traslado exitoso de los bienes comerciales, aspectos de difícil articulación para el experto residente en Buenos Aires. Farro (2008) destaca además que relaciones basadas en formas de parentesco ritual, como el compadrazgo, fueron muy comunes en la región y posiblemente se involucrasen en estas redes en amplias escalas espaciales.

\section{Tipos y cantidad de piezas}

Fueron varios los estudiosos que se acercaron a Zavaleta para comprar colecciones o conocer sus piezas arqueológicas y no arqueológicas. Debe recordarse que Zavaleta inicia su actividad tan temprano como 1885 , siendo un momento de ávido interés por una región apenas explorada. Detrás subyace la necesidad de adquirir grandes colecciones para completar las exhibiciones de los salones de museos nacionales e internacionales en un área de vacancia de material y de poseer muestras comparativas con otras regiones, fundamentalmente del área andina, en un momento de consolidación del campo científico de la arqueología y otras disciplinas.

Al ser consultado acerca del segundo lote comprado en el Congreso en 1907, Ameghino destacaba que:

El propietario hace resaltar que el Honorable Congreso le compró, por la cantidad de 50.000 pesos moneda nacional una colección que constaba tan sólo de dos 
mil nueve piezas, mientras que la colección actual consta de once mil quinientos noventa ejemplares. Sin embargo, no es por el número de ejemplares que debe juzgarse del valor de la colección, sino por la calidad de las piezas (...) entre los 11.590 objetos, más de 6.000 son puntas de flecha, en piedra, su valor es casi nulo (...) los primeros objetos calchaquíes coleccionados veinte años ha debían de tener un valor muchísimo mayor que en el día de hoy, pues desde entonces se los ha recogido en grandes cantidades (Ameghino, 1936, p. 102).

Concluía diciendo que:

No quiero decir con esto que la nueva colección del señor Zavaleta esté desprovista de importancia. Su valor consiste en el número relativamente considerable de objetos (...), cuya recolección y transporte ha exigido indudablemente la inversión de sumas bastante elevadas (Ameghino, 1936, p. 102).

Más de 20 años después, las colecciones mismas se insertan dentro de los principios de oferta y demanda comercial por lo que fue perdiendo valor por la sobresaturación de los objetos como mercancía. Y sin embargo, las colecciones seguían siendo solicitadas y compradas, de forma que el estado seguía jugando un rol fundamental.

\section{Destino final de las colecciones}

Otro elemento clave que Zavaleta supo aprovechar para lograr beneficios económicos fue el destino final de las colecciones. Cuando se produce la primer venta a través del Congreso, las opiniones de los consultados resaltan que vale la pena conservar las piezas en el país pero no aceptan fijar un precio porque no se trata de "artículos de comercio" (Lenton, 2005). Con un interés en los hallazgos arqueológicos como representantes del antiguo habitante indígena, Quiroga recordaba a Zavaleta:

Sus deberes y sentimientos de argentino para que esta colección quede en el país, figurando en los estantes de nuestros Museos, porque de otro modo se van al extranjero los elementos seculares de estudio de nuestra prehistoria (Quiroga, 1896, p. 210).

Sus argumentos también van dirigidos hacia el reconocimiento del valor de las piezas como parte de la prehistoria de la nación. Ambrosetti manifestaba, a propósito de un análisis realizado sobre los usos de las urnas de la colección Zavaleta expuesta en París, que: "la arqueología de cualquier país es necesario estudiarla en el mismo territorio donde se hallan los objetos, haciendo excavaciones y explorando personalmente los yacimientos" (Ambrosetti, 1897, p. 36).

Independientemente de los argumentos de análisis esgrimidos, ante un precio poco conveniente o ausencia de respuestas por parte del entorno local, Zavaleta podía organizar giras internacionales para lograr su venta. Lenton sugiere que la primer venta mediante el Congreso de la Nación en 1899 se debe a que Zavaleta quiso "obtener alguna remuneración por esta colección que ya había cedido al Museo en algún momento previo, posiblemente por haber recibido ahora alguna oferta del extranjero" (Lenton, 2005, p. 194).

\section{Zavaleta, comerciante tolerado e impulsor de cambios}

La “colección Zavaleta” en su amplia dispersión mundial permite observar cambios en un momento clave de la consolidación de la arqueología y del rol del estado en la preservación de los objetos arqueológicos, donde el interés en mantener el patrimonio arqueológico en el país es clave (Lenton, 2005). En 1913 se promulga la 
Ley $\mathrm{N}^{\circ} 9080$ que declara como propiedad de la Nación a las ruinas y yacimientos arqueológicos y paleontológicos, nombrando asesores permanentes a la Dirección del Museo Nacional de Historia Natural y a la Dirección del Museo Etnográfico de Buenos Aires y que establece como deber de la Nación conservar los restos de civilizaciones antiguas, prohíbe la comercialización de las piezas halladas y autoriza expropiar las colecciones privadas existentes. Esta ley constituyó la primera preocupación por regular específicamente la protección del patrimonio arqueológico y paleontológico de Argentina (Lenton, 2005), si bien la actividad de coleccionistas continuó y estas instituciones ignoraron su función de gestores (Endere y Rolandi, 2007). De este modo y en términos de Lenton: "el affaire de la colección Zavaleta inauguró una serie de manifestaciones de una nueva 'preocupación' política por lo que comienza a definirse como 'riqueza cultural' en peligro" (Lenton, 2005, p. 196). Palamarczuk y Grimoldi recuperan información aportada por pobladores a Debenedetti en Fuerte Quemado, quien en 1920 escribía: “Zavaleta reunió mucho material y lo mismo Salvatierra y Schreiter. Todos estos señores resultaron vulgares comerciantes" (Palamarczuk y Grimoldi, 2016, p. 79).

Independientemente de la real aceptación o no que Zavaleta gozara entre sus contemporáneos, supo entretejer sus intereses económicos personales con aquellos del estado, de las instituciones científicas, de los investigadores contemporáneos y de la prensa. El accionar de Zavaleta se imbrica en una compleja red que articulaba contactos locales y regionales para lograr la recolección de una variedad de piezas, que cruzaban la frontera nacional, con expertos académicos que legitimaban los objetos por él comercializados, con la prensa que seguía sus colecciones y lo describían como autoridad en la arqueología del país, con el estado nación que compraba sus piezas para los museos nacionales y auspiciaba su presencia internacional y venta de artefactos arqueológicos a otros países. Si bien hubo muchas voces en contra dentro del ámbito académico, éste terminó favoreciendo las actividades de Zavaleta por el interés de adquirir piezas únicas y escasas y evitar que fueran vendidas al exterior. Zavaleta aprovechó exitosamente una encrucijada clave de formación institucional de la práctica arqueológica pero a su vez fue objeto de reflexión y de medidas legales concretas para finalmente generar un consenso político y científico acerca de los métodos y técnicas de recuperación y adquisición de piezas.

Los alcances de la práctica de huaqueo de Zavaleta fueron nuevamente reconocidos en la década de 1980, cuando González postula que cuatro figuras rituales en madera depositadas en el Museo de Berlín habrían sido todas halladas en un mismo sitio. Sin embargo, en los registros de la institución existe información sobre dos procedencias diferentes, lo que podría deberse al interés de Zavaleta de "preservar para sí los lugares de origen de sus saqueos (...), ya que se trataba de alguien cuyo único interés era el comercio de especímenes arqueológicos, base de su fortuna personal" (González, 1983, p. 227). Algo similar ocurre con la figurina femenina de piedra que según consta en trabajos publicados previamente es de Molinos pero en los registros de FMC es de San Carlos. De este modo, no debería llamar la atención que los materiales arqueológicos pertenecientes a los mismos contextos estén separados y asignados a otros lugares o inclusive estén depositados en distintas instituciones hoy día?

\section{Conclusiones}

Este trabajo se propuso recorrer las sendas materiales de un conjunto de piezas arqueológicas, aquellas vendidas por Manuel Zavaleta al FMC en 1904. De las 4.565 piezas, la mayoría aun pertenece a dicha institución, aunque renumeradas. Apenas se conoce dónde fueron halladas, sabiendo que pertenecen a las provincias de Salta, Tucumán y Catamarca. Zavaleta informaba únicamente el área regional de hallazgo
7. No debemos descartar errores humanos en la designación de los materiales a los contextos. En el FMC existen procedencias mal escritas que pudieron resultar de momentos posteriores a la adquisición original. El hecho de que Zavaleta adjuntó una fotografía de él mismo con las cuatro figuras de madera, resaltando en la misma una única procedencia abre lugar a este interrogante. 
(a nivel de localidad, por lo general), evitando así el surgimiento de competidores. Hay otras causas posibles detrás de este desconocimiento, como errores cometidos por terceros a la hora de trascribir las procedencias. Pero mucho más fundamental es que la práctica arqueológica de la mayoría de los estudiosos de entonces de la cultura calchaquí no era especialmente diferente, ya que se priorizaba la recuperación de los objetos, su resguardo en museos nacionales y se le otorgaba primacía a lo único por oposición a lo repetido. Estas circunstancias de la arqueología explican el éxito de Zavaleta en un ámbito académico que criticaba sus negocios con las antigüedades calchaquíes. Si bien tempranamente la metodología de trabajo de campo fue bosquejada por lo que Haber (1994) llamó "corriente naturalista", pocas veces fue precisa y se guió por principios estratigráficos. En el NOA por lo general las excavaciones eran realizadas con pala y a cargo de peones (González, 1985) y solo el material museable era recolectado. Del mismo modo, los esqueletos humanos no eran recuperados en su totalidad privilegiando la búsqueda de cráneos en buenas condiciones. En este sentido, minimalista no era una característica única de Zavaleta sino de la gran mayoría de las intervenciones en el campo de ese período, limitándose el arqueólogo a tomar notas de los hallazgos, realizando croquis y esquemas de las piezas (González, 1985).

Si la estructura del campo científico se define en cada momento por el estado de las relaciones de fuerza entre los protagonistas de la lucha, agentes o instituciones, es decir por la estructura de la distribución del capital específico, resultado de luchas previas cristalizadas en las instituciones y las disposiciones, y que dirige las estrategias y las posibilidades objetivas de los diferentes agentes o instituciones en las luchas presentes (Bourdieu, 2000), tenemos entonces un proyecto político de modernización impulsado por la clase dirigente que promovía la constitución de instituciones y sociedades científicas, universidades modernas con profesores e intelectuales europeos, la generación de grandes museos que albergaban objetos pretéritos y orgulloso de la nueva sociedad en gestación (Babot, 1998). Y por otro lado, la urgencia de abastecer estos últimos de piezas únicas, hasta ese entonces poco numerosas, susceptibles de narrar con una sola mirada, un mundo exótico, lejano temporal y espacialmente de las grandes ciudades argentinas. Se esbozaba así un pasado glorioso pero ajeno a la nueva nación.

Zavaleta se aprovechó de las tensiones no solo personales e institucionales sino también de las formas de aproximarse - y las motivaciones a hacerlo- a las piezas arqueológicas. Personaje conflictivo en el ámbito académico, sus adquisiciones demostraban la poca coherencia entre políticas, convicciones y prácticas. La venta de la porción Zavaleta en Chicago refleja una vez más esas tensiones, donde el gobierno nacional acudió a Zavaleta que, con ventas de piezas arqueológicas que llevó bajo su propio riesgo económico, ocupó un espacio vacío de contenido nacional. A este contexto académico-institucional debe recordarse las actividades económicas que paralelamente llevaba a cabo Zavaleta en los valles Calchaquíes y zonas aledañas. Es decir, Zavaleta superó a escala local una serie de dificultades y logró atravesarla para articular museos nacionales, autoridades académicas y legislativas e interesados extranjeros y público general mediante la prensa. A lo largo del período que abarcó su actividad comercial empleó diversas estrategias sociales que le permitieron apropiarse del capital simbólico necesario para articular redes de acción tan dispares, el cual le proporcionó nuevo capital económico ${ }^{8}$.

. Uhle estaba sorprendido de que avaleta hubiera logrado comprar una máquina para hacer hielo mediante la venta de antigüedades, cuyas ganancias le facilitaron aún más establecer nuevas colecciones arqueológicas y de historia natural (Fischer, 2010, p. 53).
Parezo y Munro (2010) realizan un análisis de las colecciones arqueológicas y etnográficas llevadas por México, Brasil y Argentina a Saint Louis. Dado el contraste ya enunciado entre la feria de París y la de Saint Louis en el pabellón argentino, las autoras consideran que el mismo respondió a dispares proyectos nacionales planificados, quizá inspirado en el gobierno mexicano que envío materiales para 
promover una historia nacional que demostrase simultáneamente la distancia de la nación de su legado español colonial como el firme control territorial sobre las poblaciones indígenas (Parezo y Munro, 2010). Si tenemos en cuenta algunos elementos, tales como el poco interés despertado por el gobierno argentino de participar en la feria, las políticas generales en torno al indígena, como proceso en estado de extinción inevitable en pos del progreso (Gluzman, 2013), la creciente importancia del componente hispánico en la construcción nacional encarnado en la figura idealizada del gaucho en desmedro del indígena (De Jong, 2005), cuesta concebir un cambio significativo en la estrategia política indigenista entre las ferias. Si bien solo habían pasado 15 años entre las ferias, hacia 1889 las ocupaciones militares de Chaco y Patagonia era aun recientes. No es casual que la feria en Francia resaltara el matiz cosmopolita de Buenos Aires, la París de Sudamérica, y el interior del país aun por ser habitado por inmigración europea. Por tal motivo, no había rastro de población indígena, pasada o presente en la exposición del país (Fey, 2004) ${ }^{9}$.

La comprensión de cómo Zavaleta se involucró dentro del campo científico permite darle más importancia a que éste reconocía el interés de los museos estadounidenses en las culturas prehispánicas y a su beneficio netamente económico. Por tal motivo más que un énfasis en la continuidad entre una civilización prehispánica y la sociedad contemporánea, las vitrinas del pabellón argentino deben leerse como lo contrario, una sucesión de piezas enteras o fragmentadas con poca o nula descripción, que encierra una perspectiva pasada y muerta acerca de los momentos previos a la constitución nacional. El país fue orgullosamente representado en otros ámbitos dentro de la feria, como el que hace a las Bellas Artes, que si bien se presentó modestamente, no hubo manifestación alguna acerca de la temática indígena ya que Schiaffino, a cargo del envío de selección de las obras, buscó colecciones que retrataban una nación de perfil europeo, pero con identidad propia y liderazgo latinoamericano (Penhos, 2009). En 1889 Zavaleta ya había vendido algunas de sus colecciones y gozaba de renombre en el ámbito de los museos e instituciones. Sin embargo la exposición de París refleja aun la sensibilidad por el tema indígena. En 1904, éste representaba el momento anterior a la nación, herencia a mostrar como etapa superada y a los mismos objetos en las vitrinas bajo el control del estado argentino. La participación de Zavaleta con su fastuosa colección ante la prensa nacional e internacional y ante los visitantes y organizadores de la feria refleja para nosotros la escasa preocupación por el tema indígena a inicios del siglo XX, al punto tal de haber dejado la representación de la relación de la nación y los pueblos indígenas contemporáneos mediante materiales organizados por Zavaleta. En las vitrinas donde yacía esta acumulación de objetos ya se podía vislumbrar el incierto paradero futuro de estas sociedades y su cultura material. Descontextualizadas y encerradas en vitrinas, las piezas de la colección Zavaleta quedaron expuestas como curiosidades alejadas de su sentido de estudio (Podgorny, 2009). Sin embargo el FMC supo luego revertir la situación, como lo demuestra su actual interés en su estudio y sistematicidad en su organización material.

No debe perderse de vista a los 4.565 objetos arqueológicos de la colección Zavaleta adquiridos por el FMC. Aquí se ha analizado su trayectoria histórica tras su hallazgo y se ha reflexionado acerca a los espacios de poder y de los ámbitos de intereses sociales dispares donde los mismos entraron en juego. Nacionalidad, competencia de saberes, búsqueda de conocimiento y de reconocimiento y racismo, entre otros aspectos, han sido instrumentados mediante los mismos. Los objetos arqueológicos continúan siendo lo que fueron en otros tiempos, producto de la cultura material que puede participar en la vida social de un grupo humano fomentando activamente a la construcción de relaciones sociales, de valores y de decisiones (Appadurai, 1991). Los objetos nos unen al pasado y es nuestra responsabilidad como arqueólogos también contribuir a su presente y futuro.
9. Fey (2004) comenta que durante la exposición una francesa solicitó fotografías de salvajes en el pabellón y amablemente se le explicó que ya no había, que se habían mudado a las ciudades y eran por entonces ciudadanos educados y apreciados. Como prueba, se le presentó un empleado, descendiente directo de un cacique poderoso. 


\section{Agradecimientos}

Al Field Museum of Natural History de Chicago por haberme otorgado una beca para revisar parte de la colección Zavaleta (2013). En particular agradezco a Christopher Philipp, director de las colecciones de Antropología, Cassie Pontone, asistente de dirección de colecciones, Dr. Ryan Williams, Curador de Antropología y Jefe de Sección de Ciencias Sociales, Dr. Robert Lucking miembro del Comité de Becas, Dra. Laure Dussubieux directora del laboratorio del área, Nina Cummings, archivista de fotografía, Armand Esai, archivista del museo y Gary Drimmer, guía del museo especializado en América del Sur. 


\section{Referencias citadas}

" Accession № 894 (1904). Archivo acerca del material arqueológico, colección Zavaleta. The Field Museum of Natural History, Chicago.

» Accession N 971 (1905). Archivo acerca del material óseo humano, colección Zavaleta. The Field Museum of Natural History, Chicago.

"Ambrosetti, J. B. (1897). La antigua ciudad de Quilmes (valle Calchaquí). Boletín del Instituto Geográfico Argentino, 18, 33-70.

"Ambrosetti, J. B. (1899). Notas de arqueología Calchaquí. Buenos Aires: Imprenta La Buenos Aires.

»Ameghino, F. (1891). Sobre algunos restos de mamíferos fósiles, recogidos por el señor Manuel B. Zavaleta en la formación miocena de Tucumán y Catamarca. Revista Argentina de Historia Natural, 1(2), 88-101.

"Ameghino, F. (1936). Obras completas y correspondencia científica de Florentino Ameghino. La Plata: Gobierno de la Provincia de Buenos Aires.

》 Appadurai, A. (1991). Introducción: las mercancías y la política del valor. En A. Appadurai (Ed.), La vida social de las cosas. Perspectiva cultural de las mercancías (pp. 17- 87). México: Grijalbo.

》 Argentina. Ministerio de Justicia, Culto e Instrucción Pública (1897). Registro nacional de la República Argentina que comprende los documentos espedidos desde 1810 a 1890. Buenos Aires: Taller topográfico de la Penitenciaria Nacional.

" Argentina. Ministerio de Justicia, Culto e Instrucción Pública (1899). Registro nacional de la República Argentina que comprende los documentos espedidos desde 1810 a 1890. Buenos Aires: Taller topográfico de la Penitenciaria Nacional.

》Argentinos en la exposición de San Luis (1904, octubre, VII-313). Caras y Caretas, p. 21.

"At the White House (1904, junio). New York Tribune, p. 8.

" Babot, M. P. (1998). La arqueología argentina de fines del siglo XIX y principios del XX a través de J.B. Ambrosetti. Mundo de Antes, 1, 165-192.

» Bertone, M. R., Lareo, J., Montales, E., Tenewick, I., Stivala, A. y Boote, S. (1991). Tratamiento de la cuestión indígena (Serie Estudios e investigaciones 2). Buenos Aires: Dirección de Información Parlamentaria del Congreso de la Nación.

》Bourdieu, P. (2000). Los usos sociales de la ciencia. Buenos Aires: Nueva Visión.

" Buel, J. (1904). Louisiana and the Fair: an exposition of the world, its people and their achievements 6. St. Louis: World's Progress Pub. Co.

" Burmeister, G. (1891). Adiciones al examen crítico de los mamíferos fósiles tratados en el artículo IV anterior. Anales del Museo Nacional de Buenos Aires, 3, 375-399.

" Chicago gets rare relics. South American Collection at St. Louis is purchased by Field Columbian Museum (1904, noviembre). The News-Herald.

"Comisión Argentina en la exposición de San Luis (1904, agosto, Vll-308). Caras y Caretas, p. 31.

" Coronet Instructional Films. (Productor). (1947) ¿Qué es el dinero? Recuperado de https://www.youtube.com/watch?v=-ANcnBw_gLk (Acceso: 15 de octubre, 2016). 
》De Asúa, M. (2012). Dos siglos y un museo. En E. Penchaszadeh (Ed.), El Museo Argentino de Ciencias Naturales (pp. 13-70). Buenos Aires: MACN.

"De Jong, I. (2005). Entre indios e inmigrantes: el pensamiento nacionalista y los precursores del folklore en la antropología argentina del cambio de siglo. Revista de Indias, 65, 405-426.

» de la Vaulx H. (1901). Excursion dans les vallées Calchaquies (province de Tucuman). Poteries indigènes. Journal de la Société des Américanistes, 3(2), 168-176.

»Dorsey, G. (1900). The Department of Anthropology of the Field Columbian Museum. A Review of Six Years. American Anthropologist New Series, 2(2), 247-265.

»Endere, M. L. y Rolandi, D. (2007). Legislación y gestión del patrimonio arqueológico. Breve reseña de lo acontecido en los últimos 70 años. Relaciones de la Sociedad Argentina de Antropología, XXXII, 33-54.

"Exhibit of Argentina's Prehistoric People. Remarkable Collection of Relics sent to World's Fair by Manuel Zavaleta (1904, 26 de junio). The Washington Times, p. 12.

" Fabian, J. (2002). Time and the Other: How Anthropology Makes its Object. Nueva York: Columbia University Press.

» Farro, M. (2008). Historia de las Colecciones en el Museo de La Plata, 1884- 1906: naturalistas viajeros, coleccionistas y comerciantes de objetos de historia natural a fines del siglo XIX. (Tesis Doctoral inédita), Universidad Nacional de La Plata, Argentina.

» Fey, I. (2004). Peddling the Pampas: Argentina at the Paris Universal Exposition of 1889. En W. Beezley y L. Curcio-Nagy (Eds.), Latin American Popular Culture: introduction (pp. 61-86). Wilmington: SR Books.

》 Field Museum of Natural History (1919). Annual report of the director to the board of trustees for the year 1918. En Field Museum of Natural History Publication 202. Report Series (Volumen 5, número 4).

" First Exhibit Sold (1904, octubre). The St. Louis Republic, p. 6.

» Fischer, M. (2010). La misión de Max Uhle para el Museo Real de Etnología en Berlín: entre las ciencias humboldtianas y la arqueología americana. En P. Kaulicke, M. Fischer, P. Masson y G. Wolff (Eds.), Max Uhle (1856-1944). Evaluaciones de sus investigaciones y obra (pp. 49-62). Lima: PUCP.

» Francis, D. (1913). The universal exposition of 1904 (Volumen 1). Saint Louis: Louisiana Purchase Exposition Co.

»González, A. (1983). Notas sobre religión y culto en el Noroeste argentino prehispánico. A propósito de unas figuras antropomorfas del Museo de Berlín. Baessler- Archiv für Volkerkunde, Neue Folge, XXXI, 212-282.

»González, A. (1985). Cincuenta años de arqueología del noroeste Argentino (1930-80): apuntes de un casi testigo y algo de protagonista. American Antiquity, 50(3), 505-517.

" Gluzman, G. (2013). Narrativas arqueológicas del momento de contacto en los valles Calchaquíes. Revista Arqueología, 19, 107-129.

" Haber, A. (1994). Supuestos teórico-metodológicos de la etapa formativa de la arqueología de Catamarca (1875-1900). Publicaciones Arqueología, 47, 31-54.

" Haber, A. (1999). Caspinchango, la ruptura metafísica y la cuestión colonial en la arqueología sudamericana: el caso del noroeste argentino. Revista du Museu de Arqueologia e Etnologia, 3, 129-141.

» Hewett, E., Moore, C., Boas, F., Hrdli ka, A., McGuire, J., Smith, H., Culin, S., Tooker, W. y Swanton, J. (1905). Anthropologic Miscellanea. American Anthropologist, New Series, 7(1), 157-173. 
» Holmberg, E. (1887). Viaje a Misiones. Boletín de la Academia Nacional de Ciencias en Córdoba, X, 5-392.

»La Nación (1904, 17 de noviembre). Venta de la colección Zavaleta. http://www.lanacion. com.ar/654668-cien-anos-atrás

»Lenton, D. (2005). De Centauros a protegidos. La construcción del sujeto de la política indigenista, desde los debates parlamentarios (1880-1970). (Tesis Doctoral inédita), Universidad de Buenos Aires, Argentina.

» Lewis, P. (1961). A Definition of Primitive Art. Fieldiana Anthropology, 36(10), 221-241.

» Louisiana Purchase Exposition (1904). Official Catalogue of Exhibitors Universal Exposition. St. Louis, Division of exhibits. St. Louis: Official Catalogue Co.

»Louisiana Purchase Exposition Commission (1906). Final Report of the Louisiana Purchase Exposition Commission. Washington: Government Printing Office.

» Notes of Happenings at the World's Fair (1904, agosto). The St. Louis Republic, p. 9.

»Official Guide Company (1904). World's fair authentic guide; complete reference book to St. Louis and the Louisiana purchase exposition. Saint Louis: Official Guide Company.

»Palamarczuk, V. y Grimoldi, S. (2016). Un manuscrito inédito de Rudolf Schreiter sobre arqueología del noroeste argentino. Relaciones entre coleccionismo e investigación científica a comienzos del Siglo XX. Revista del Museo de Antropología, 9(2), 67-80.

»Parezo, N. y Fowler, D. (2007). Anthropology Goes to the Fair: The 1904 Louisiana Purchase Exposition. Lincoln: University of Nebraska Press.

»Parezo, N. y Munro, L. (2010). Bridging the Gulf: Mexico, Brazil, and Argentina on display at the 1904 Louisiana Purchase Exposition. Studies in Latin American Popular Culture, 28, 25-47.

》Pegoraro, A. (2009). Las colecciones del Museo Etnográfico de la Universidad de Buenos Aires: un episodio en la historia del americanismo en la Argentina 1890-1927. (Tesis Doctoral inédita), Universidad de Buenos Aires, Argentina.

»Penhos, M. (2009). Saint Louis 1904. Argentina en escena. En M. S. Di Liscia y A. Lluch (Coords.), Argentina en exposición. Ferias y exhibiciones durante los siglos XIX y XX (pp. 5984). Sevilla: Consejo Investigaciones Científicas.

»Peña de Bascary, S. (2014). La colección arqueológica Alberto Paz Posse. Historia y cultura: Tucumán y el noroeste argentino, 1, 4-87.

»Petitjean, H. (1897). La collection Zavaleta. Journal de la Société des Américanistes, 4(1), 231-233.

»Podgorny, I. (2009). El sendero del tiempo y de las causas accidentales: los espacios de la prehistoria en la Argentina, 1850-1910. Rosario: Prohistoria.

»Quiroga, A. (1896). Antigüedades calchaquíes. La colección Zavaleta. Boletín del Instituto Geográfico Argentino, 17, 177-210.

"Scars on skulls interest scientist (1904, agosto). The St. Louis Republic, p.14.

»Scattolin, M. C. (2003). Los ancestros de calchaquí: una visión de la Colección Zavaleta. Cuadernos de la Facultad de Humanidades y Ciencias Sociales, 20, 51-79.

»Scattolin, M. C. (2006a). Contornos y confines del universo iconográfico precalchaquí del valle de Santa María. Estudios Atacameños, 32, 119-139.

»Scattolin, M. C. (2006b). La mujer que carga el cántaro. En V. Willians y B. Alberti (Eds.), Género y Etnicidad en la Arqueología Sudamericana (pp. 43-71). Olavarría: UNICEN.

»Starr, F. (1905). Anthropology at the St. Louis Exposition. The American Antiquarian and Oriental Journal, 27(1), 40-42. 
"Stevens, W. B. (Comp.) (1904). Official Directory of the Louisiana Purchase Exposition, World's Fair, Saint Louis. St. Louis: Woodward \& Tiernan Printing Co.

» Tarragó, M. (2003). La Arqueología de los Valles Calchaquíes en perspectiva histórica. En P. Cornell y P. Stenborg (Eds.), Anales. Nueva Época 6: "Local, regional, global, prehistoria, protohistoria e historia en los Valles Calchaquíes” (pp. 13-42). Göteborg: Instituto Iberoamericano, Universidad de Göteborg.

» Ten Kate, H. (1893). Rapport sommaire sur une excursión archéologique dans les provinces de Catamarca, de Tucuman et de Salta. Revista del Museo de La Plata, V, 329346.

"Weber R. (1978). A seriation of the Late Prehistoric Santa María Culture of Northwestern Argentina. Fieldiana Anthropology, 68(2), 49-98.

»Weber R. (1981). An analysis of Santa Maria urn painting and its cultural implications. Fieldiana Anthropology, 2, 1-32.

"Williamson, S. (2017). Seven Ways to Compute the Relative Value of a U.S. Dollar Amount, 1774 to present, https://www.measuringworth.com/uscompare/relativevalue. php (Acceso: 15 de febrero, 2017).

"Zavaleta, M. (1906). Catálogo de la colección Calchaquí de Arqueología y Antropología. Buenos Aires: Imprenta y Librería Petenello Hnos. 